Reprod. Nutr. Dévelop. 1980, 20 (4 A), 983-990.

\title{
Origin of high slow-wave frequency in the dog colon
}

\author{
par J. FIORAMONTI, L. BUENO, S. K. SARNA *, Y. RUCKEBUSCH \\ Laboratoire de Physiologie, Ecole Nationale Vétérinaire, \\ 23, chemin des Copelles 31076 Toulouse Cedex, France. \\ * Depariment of Surgery and Electrical and Computer Engineering \\ McMaster University, Hamilton, Canoda.
}

Summary. Using intraparietal and intraluminal electrodes, duodenal and colonic electrical activities were simultaneously recorded in dogs under pentobarbital anaesthesia to study the temporal relationship between the slow-wave frequency of the colon and that of the proximal duodenum.

The colonic electromyogram showed two distinct slow-wave frequencies, one in the range of 7-9 cycles/min, and the other in the range of 18-19 cycles/min. The latter was synchronized to that observed on the duodenum, and disappeared after removal of the entire duodenum and the proximal jejunum over $90 \mathrm{~cm}$, from 8 to $98 \mathrm{~cm}$ from the pylorus.

After transversally cutting the muscular layers of the duodenum at $8 \mathrm{~cm}$ from the pylorus, the high slow-wave frequency of the colon decreased to $16-16.5$ cycles $/ \mathrm{min}$, similarly to that observed on the duodenum aborally to the section. When another section was performed $5 \mathrm{~cm}$ aborally to the first cutting level, the colonic slow-wave frequency was again synchronized to that of the duodenum observed aborally to the second section. Intraduodenal infusion of cold water decreased the amplitude of both the duodenal and the colonic slowwaves by 50 p. 100 and the frequency by 30 p. 100.

Since all these experimental procedures did not affect the colonic slow-wave frequency at 7-9 cycles/min, and no temporal relationship was found between duodenal and colonic spiking activities, it was concluded that (i) the colonic slow-wave frequency at $18-19 \mathrm{cycles} / \mathrm{min}$, recorded from both the intraparietal and the intraluminal electrodes in dog, was an « artefact » of duodenal activity acting as an electric dipole and (ii) that the only slow-wave frequency of 7.9 cycles/min was generated by the colon.

\section{Introduction.}

The slow-waves in the stomach and the small intestine are regular and of sufficient amplitude to be readily recorded from both the serosal and the intraluminal electrodes without any ambiguity. On the other hand, the slow-wave frequency in the human colon is highly irregular, time varying and of low amplitude so that computerized analysis of the recording is often necessary to determine the frequency. 
In dogs, several investigators have reported two distinct frequencies in the colon, one in the range of $5-7 \mathrm{c} / \mathrm{min}$ and the other in the range of $18-20 \mathrm{c} / \mathrm{min}$ (Bueno ef al., 1977 ; Caprilli et al., 1975). These frequencies are in the range of gastric and duodenal slow-wave frequencies, respectively, in the dog. It is therefore pcssible that their presence in the colonic recordings is an artefact rather than a real colonic signal. Recently, Lord et al. (1979) still recorded « the rapid slow-wave » from the proximal colon 30 min after excision of the canine small bowel. In contrast, El Sharkawy et al. (1979) only found in vitro « omnipresent periodic membrane depolarizations » at frequencies ranging from 3.9 to $6.4 \mathrm{c} / \mathrm{min}$.

The purpose of this study is to determine the origin of these two frequencies recorded in vivo in the dog colon. Changes in the duodenal slow-wave frequency were induced by section and cooling to record the subsequent alterations, if any, of the colonic slow-wave frequency.

\section{Material and methods.}

Two healthy dogs weighing 18 to $20 \mathrm{~kg}$ were surgically implanted with 8 pairs of Trimel nichrome wire bipolar electrodes, as described previously (Ruckebusch, 1970). Three pairs of electrodes were fixed in the duodenum at 5,10 and $15 \mathrm{~cm}$ from the pylorus, three in the jejunum at 10,60 and $110 \mathrm{~cm}$ from the ligament of Treitz, and the remaining two pairs in the colon at 10 and $30 \mathrm{~cm}$ from the ileo-colonic junction. An additional pair of electrodes was inserted on the great curvature of the antrum at $10 \mathrm{~cm}$ from the pylorus.

The dogs were allowed to recover for 3 days. On the 4th day, they were anaesthetized with $30 \mathrm{mg} / \mathrm{kg}$ of sodium pentobarbital. We positioned in the colon an intraluminal probe consisting of a polyvinyl tube $1 \mathrm{~cm}$ in diameter, supporting at $10 \mathrm{~cm}$ intervals three pairs of annular electrodes $5 \mathrm{~mm}$ apart (Bueno ef al., 1977), so that the proximal pair of electrodes was about $10 \mathrm{~cm}$ from the ileo-colonic junction.

All the recordings were made on a multichannel EEG recorder with the upper and lower cut-off frequencies set at $0.5 \mathrm{~Hz}$ and $80 \mathrm{~Hz}(-3 \mathrm{~dB})$, respectively. After 30 min of control recording, a cut was made on the muscle layers distal to the first duodenal electrode site at $8 \mathrm{~cm}$ from the pylorus. A similar incision was made distal to the second pair of electrodes after an additional 30 min recording period. $300 \mathrm{ml}$ of cold saline $\left(9 \%\right.$ ) af $1{ }^{\circ} \mathrm{C}$ was injected in 3 to $5 \mathrm{~min}$ into the duodenum at the site of the second electrode, and the recording was continued for $20 \mathrm{~min}$.

Neostigmine (Prostigmine N. D.) then was given intravenously $(2 \mathrm{mg} / \mathrm{kg})$, and at the end of the experiments we removed the duodenum and the proximal jeiunum from site of the first incision to $98 \mathrm{~cm}$ from the pylorus.

The electromyograms of the remaining electrodes of the colon were recorded during 10 to $20 \mathrm{~min}$ before euthanasia with $200 \mathrm{mg} / \mathrm{kg}$ of sodium pentobarbital. Excision of the small bowel was interrupted when no high slow-wave frequency was recorded on either the intraparietal or the intraluminal colonic electrodes. The slowwave frequencies were finally determined by counting their number over $10 \mathrm{~min}$ periods ; in addition (table 1), synchronization between the duodenal and the colonic slow -waves was identified by tracing vertical lines (fig. 1-4). 


\section{Results.}

Effects of duodenal section. - All three pairs of duodenal electrodes were in the frequency plateau region and showed a regular frequency of slow-waves in the range of 18.3 to $18.8 \mathrm{c} / \mathrm{min}$. A similar frequency could be seen at some of the electrodes in the colon. On the intraparietal electrodes, the same value as that observed on the duodenum (18-19 c/min) was present during 15 to 20 p. 100 of the recording time (fig. 1). In addition, one or two groups of electrodes in all the animals presented another rhythm varying from 7 to $9 \mathrm{c} / \mathrm{min}$ and different from that observed on the antrum. These two rhythms were also temporarily seen at the electrode sites on the probe with a predominance of slow-waves during 30 to $70 \mathrm{p}$. 100 of the electrode recording time at about $10 \mathrm{~cm}$ from the ileo-colonic junction.

After the first section of the duodenal muscle layers, the frequency in the duodenum distal to the incision dropped to between 15 and $16.5 \mathrm{c} / \mathrm{min}$ and became somewhat irregular in its period. The frequency of the colon also declined to about the same range and reflected the irregular periods on a one-to-one basis (fig. 2, table 1).

Similarly, after the second incision, the mean frequency value, on a cycle-tocycle basis at both the intraparietal and the intraluminal electrodes in the colon, corresponded to the frequency distal to the second incision, which was not significantly different from that observed on the intermediate segment of duodenum between the two sections (fig. 3).

TABLE 1

Duodenal and colonic slow-wave frequencies in dogs 1 and 2 after duodenal section, cooling and removal. Similar values in duodenum and colon are in bold face type

Slow-wave frequency (cycles/min) *

\begin{tabular}{|c|c|c|c|c|c|c|}
\hline & \multicolumn{3}{|c|}{$\begin{array}{c}\text { Duodenum } \\
\text { (cm from pylorus) }\end{array}$} & \multicolumn{3}{|c|}{$\begin{array}{c}\text { Colon } \\
\text { (cm from ileo colonic junction) }\end{array}$} \\
\hline & +5 & +10 & +15 & +10 & +30 & About $10 * *$ \\
\hline \multicolumn{7}{|l|}{$\operatorname{Dog} n^{\circ} 1$} \\
\hline $\begin{array}{l}\text { Control } \ldots \ldots \ldots \ldots \ldots \ldots \\
1 \text { st section at } 8 \mathrm{~cm} \ldots \ldots \ldots \ldots \\
\text { 2nd section at } 12 \mathrm{~cm} \ldots \ldots \ldots \ldots \\
\text { Cooling } \ldots \ldots \ldots \ldots \ldots \ldots \ldots \ldots \ldots \\
\text { Removal } \ldots \ldots \ldots \ldots \ldots \ldots\end{array}$ & $\begin{array}{l}18.6 \\
19.0 \\
19.3 \\
14.2 \\
18.9\end{array}$ & $\begin{array}{l}18.6 \\
16.2 \\
16.4 \\
13.0\end{array}$ & $\begin{array}{l}18.6 \\
15.8 \\
16.3 \\
12.3\end{array}$ & $\begin{array}{c}18.6 \text { and } 9.6 \\
9.5 \\
14.3 \text { and } 9.0 \\
9.0\end{array}$ & $\begin{array}{l}0 \\
9.5 \\
9.0 \\
9.0\end{array}$ & $\begin{array}{l}18.6 \\
16.2 \\
16.3 \\
12.3 \\
12.2\end{array}$ \\
\hline \multicolumn{7}{|l|}{$\operatorname{Dog} n^{\circ} 2$} \\
\hline $\begin{array}{l}\text { Control } \ldots \ldots \ldots \ldots \ldots \ldots \\
1 \text { st section at } 8 \mathrm{~cm} \ldots \ldots \ldots \ldots \\
\text { 2nd section at } 12 \mathrm{~cm} \ldots \ldots \ldots \ldots \\
\text { Cooling } \ldots \ldots \ldots \ldots \ldots \ldots \ldots \ldots \\
\text { Removal } \ldots \ldots \ldots \ldots \ldots \ldots \ldots\end{array}$ & $\begin{array}{l}18.4 \\
18.7 \\
18.7 \\
15.2 \\
18.4\end{array}$ & $\begin{array}{l}\mathbf{1 8 . 4} \\
\mathbf{1 5 . 3} \\
16.0 \\
15.2\end{array}$ & $\begin{array}{l}18.4 \\
15.0 \\
15.6 \\
14.6\end{array}$ & $\begin{array}{l}7.1 \\
7.5 \\
15.6 \text { and } 7.5 \\
7.3 \\
7.3\end{array}$ & $\begin{array}{l}7.1 \\
15.3 \text { and } 7.5 \\
15.6 \text { abd } 7.5 \\
15.2 \\
7.3\end{array}$ & $\begin{array}{l}18.4 \\
15.3 \\
15.6 \\
14.6 \\
14.2 \text { and } 7.3\end{array}$ \\
\hline
\end{tabular}

* Values obtained by counting the number of slow-waves for a period of 10 min starting 10 min after each experiment.

** Values recorded from an intraluminal electrode site at approximately $10 \mathrm{~cm}$ from the ileocolonic junction. 
Duodenum $(.5 \mathrm{~cm}$ from pylorus)

$18.6 \mathrm{c} / \mathrm{min}$ $\mu \vee$

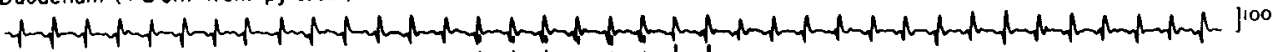
$.10 \mathrm{~cm}$

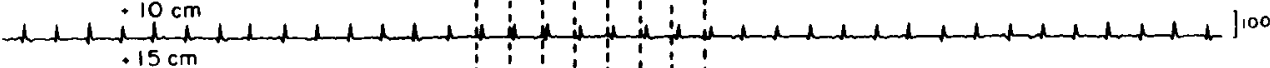

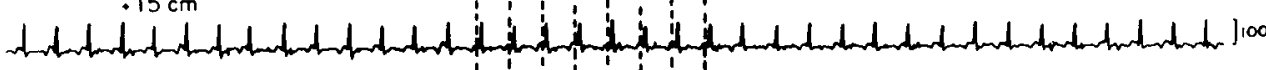
Colon $(.10 \mathrm{~cm}$ from $1 . \mathrm{CJ})$

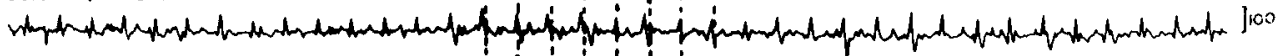
(30 $\mathrm{cm}$

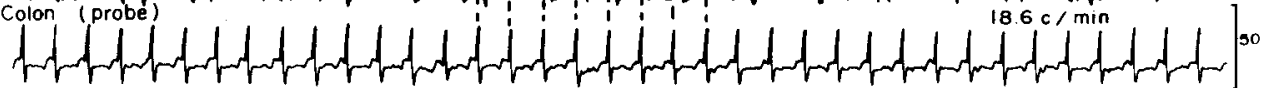

Duadenum $1.5 \mathrm{~cm}$ from pylorus )

$19.0 \mathrm{c} / \min , 100$

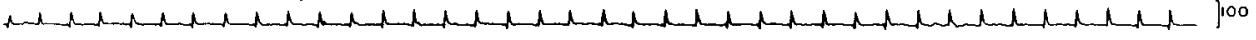
10 $10 \mathrm{~cm}$

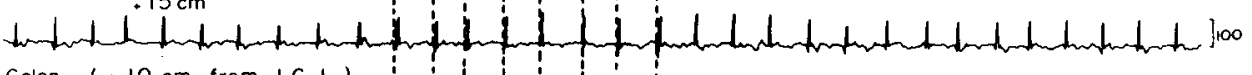
Colon $(.10 \mathrm{~cm}$ from $1 . \mathrm{CJ})$ ind $30 \mathrm{~cm}$ color (probe)

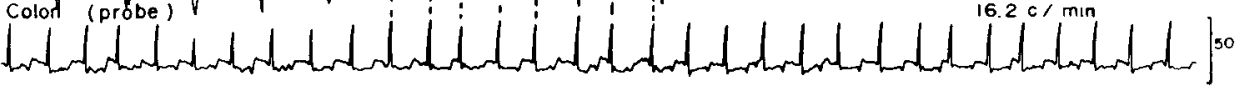

10 seconds

Duodenum $(+5 \mathrm{~cm}$ from pylorus)

$19.0 \mathrm{c} / \mathrm{min}$ $\mu v$

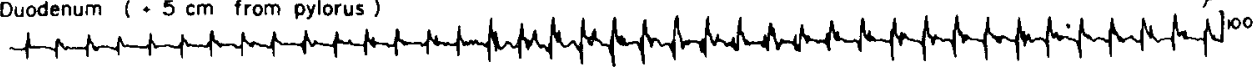
$.10 \mathrm{~cm}$

$16.4 \mathrm{c} / \mathrm{min}$ 1100

$.15 \mathrm{~cm}$

$16.3 \mathrm{c} / \mathrm{min}$

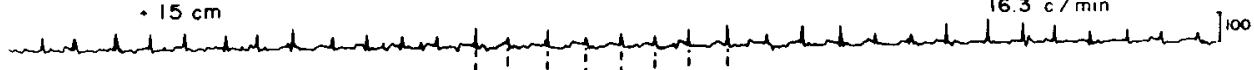

Colon (. $10 \mathrm{~cm}$ from $1 \mathrm{C} \mathrm{J.)}$

- $30 \mathrm{~cm}$ ]100

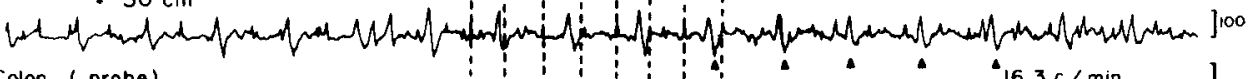
Colon (probe) 
Effect of cooling the proximal duodenum. - Cold water further reduced the slowwave frequency, recorded at the extracellular electrodes in the whole duodenum, by about 30 p. 100 and the amplitude by 50 p. 100 . Similar changes were observed in the colon, particularly in the EMG data from the intraluminal probe (fig. 4). Again, the same slow-wave frequency was recorded on both the duodenum and the colon with a very low amplitude (less than $20 \mu \mathrm{v}$ ).

Effect of neostigmine and small bowel removal. - The neostigmine caused the duodenum to contract with bursts of spike potentials in each cycle. The colon showed the slow-wave frequency of the duodenum but did not evidence the spike bursts potentials on either the intraparietal or the intraluminal electrodes (fig. 5). In contrast, the electrical spiking activity of the colon consisted of long (LSB) and short (SSB) spike bursts, the former (see fig. 5) occurring under barbiturate anaesthesia at a rhythm of 2 to 3 per minute, whereas the SSB were irregularly distributed during periods lasting 3 to 5 min.

Removal of the small bowel, from 8 to $98 \mathrm{~cm}$ beyond the pylorus, abolished the high slow-wave frequency of the colon at the intraparietal electrodes. No changes were recorded for the slow-wave frequency at 7-9 $\mathrm{c} / \mathrm{min}$ (see table 1). From the intraluminal electrodes, it was still possible to recorde oscillations resembling slow-waves of very low amplitude (less than $20 \mu \mathrm{v}$ ), as those recorded from the probe after cooling (fig. 5) ; their frequency corresponded exactly to the rhythms observed on the jejunum.

\section{Discussion.}

The presence of slow-waves at a constant frequency of 18-19 $\mathrm{c} / \mathrm{min}$ on the colon of the dog has been observed on chronical serosally implanted electrodes (Mizhorokova and Papasova, 1977) and during 40 p. 100 of the recording time (Lord ef al., 1979). It was recently reported that that rhythm predominated on the EMG record obtained from mucosal electrodes supported by an intraluminal tube as compared to

FIG. 1. - Slow-wove frequency of the duodenum and colon in an anaesthetized dog. The slow-waves were recorded from chronically implanted electrodes at 5,10 and $15 \mathrm{~cm}$ from the pylorus and at 10 and $30 \mathrm{~cm}$ from the ileo-colonic junction. Intraluminal electrodes formed by the distal end of nichrome wires wound around a tube were placed at about $10 \mathrm{~cm}$ from the ileo-colonic junction. The dotted lines indicate a similar frequency of $18.6 \mathrm{cycles} / \mathrm{min}$ between the first duodenal electrode site and the three of the colon obtained from extraluminal and intraluminal electrodes at $10 \mathrm{~cm}$ from the ileo-colonic junction.

FIG. 2. - Effect of a single section of the duodenal muscle layers at 7-8 cm from the pylorus. The slowwave frequency of the duodenum below the section decreases to $16.2 \mathrm{cycles} / \mathrm{min}$ and a similar frequency is recorded on the colon.

FIG. 3. - Effects of a double section at 8 and of $12 \mathrm{~cm}$ from the pylorus. The colonic slow-wave frequency recorded from the intraluminal electrodes is similar to that observed on the duodenum below the 2nd section at $15 \mathrm{~cm}$ from the pylorus. The intrinsic slow-wave frequency of $7-9 \mathrm{c} / \mathrm{min}$ at $30 \mathrm{~cm}$ from the junction is indicated by triangles ( $\mathbf{\Lambda}$ ). 
that obtained from intraparietally implanted electrodes (Bueno ef al., 1977). The intermittent presence of that rhythm, as well as the absence of any significant gradient along its length, and the more selective recording by mucosal route have suggested its « muscularis mucosae» origin.

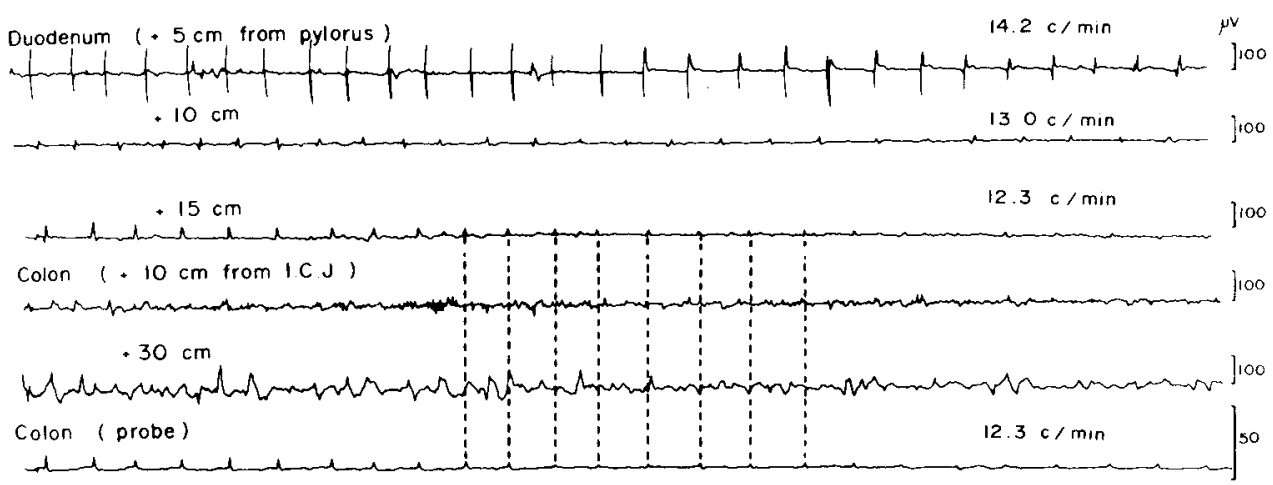

10 seconds

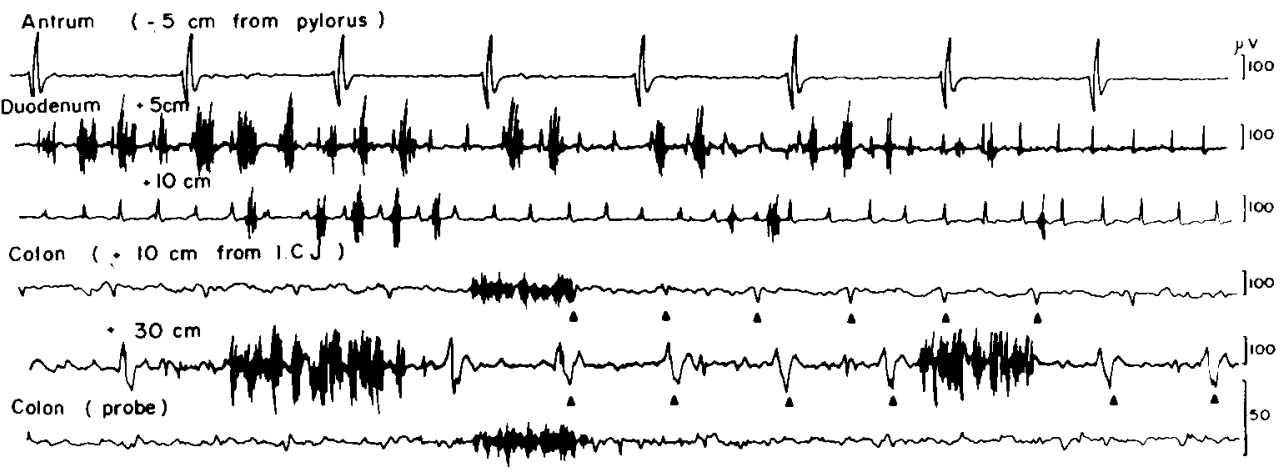

10 seconds

FIG. 4. - Reduction of amplitude and frequency of colonic slow-waves ofter duodenal cooling. The temperature of the proximal duodenum decreases due to the intraluminal infusion of $300 \mathrm{ml}$ of saline at $+1^{\circ} \mathrm{C}$. The frequency is reduced in both the duodenum and the colon.

FIG. 5. - Gastroduodenal and colonic slow-waves and spike bursts. The frequency of duodenal spike bursts is similar to that of the slow waves. The long spike bursts in the colon are not superimposed on the intrinsic slow-waves, shown by triangles.

However, in in vitro experiments on cats (Chrisiensen ef al., 1969) and dogs (Vanasin ef al., 1974 ; El Sharkawy ef al., 1979) the isolated colon presented only a low varying rhythm at $5-7 \mathrm{c} / \mathrm{min}$. Similarly, our recordings in situ on anaesthetized dogs did not show the rhythm at $18-19 \mathrm{c} / \mathrm{min}$ after removal of the major part of the small bowel. The presence of small oscillations on the probe recordings was an 
interference of the remaining distal jejunum and ileum, thus suggesting a possible duodenal origin of the slow-waves at $18-19 \mathrm{c} / \mathrm{min}$.

These results clearly demonstrate that this rhythm was an « artefact 》 of duodenal activity and that the higher frequency of slow-waves on the mucosal electrodes was probably due to the amplification level, easily obtained without noise. Our study also shows that the anatomical proximity of the duodenum and the transverse colon to the Treitz ligament in the dog and the possibility of serosal-serosal adherences after surgery are not prerequisites for recording the duodenal slow-wave frequency on colonic electrodes.

We believe that duodenal slow-wave phase-locking gives an electric dipole configuration ; the resulting potential changes are easily recorded from any point on the colon and the amplitude level depends on the position of the two recording electrodes. In fact, the active surface of the annular electrodes supported by the probe is larger than that of the intraparietal electrodes ; consequently, there is a higher probability of the probe picking up two different isopotential lines of the duodenal dipole. The fact that the duodenal rhythm observed on colonic electrodes is always associated to that observed aborally to the most aboral section agrees with this hypothesis, the controlling dipole also being formed aborally to that section. The absence of any duodenal spiking activity, recorded on the colonic electrodes for both the parietal and the intraluminal electrodes, is another argument in favor of the duodenal dipole hypothesis. Finally, the intrinsic colonic slow-wave frequency at $7-9 \mathrm{c} / \mathrm{min}$ was confirmed by the simultaneous recording of the antral electromyogram which exhibited a totally uncorrelated $5-6 \mathrm{c} / \mathrm{min}$ rhythm and gave no clue as to another source for it in the abdomen.

Reçu en novembre 1979. Accepté en janvier 1980.

Résumé. L'activité électrique du côlon chez le chien présente de façon irrégulière des ondes lentes d'amplitude variable. Leur fréquence de répéfition est d'une part de $7-9 / \mathrm{min}$, d'autre part de 18-19/min, pour des électrodes intrapariétales ou endoluminales. Le problème de l'existence d'un deuxième rythme d'ondes lentes propre au côlon reste posé, en raison de l'interférence possible du rythme électrique de base du duodénum, également voisin de 17-18/min. De plus, il n'est pas décelé in vitra et il n'est plus décelé in sifu, après exérèse d'un segment intestinal de $90 \mathrm{~cm}$ de long allant de 8 à $98 \mathrm{~cm}$ du pylore.

Les expériences suivantes ont été réalisées chez le chien anesthésié, dont on enregistre simultanément l'activité électrique duodénale à 5,10 et $15 \mathrm{~cm}$ du pylore, et colique à 10 et $30 \mathrm{~cm}$ de la jonction ileo-caeco-colique : section transversale du duodenum à $8 \mathrm{~cm}$ du pylore, suivie d'une $2^{\mathrm{e}}$ section à $12 \mathrm{~cm}$ du pylore, refroidissement localisé d'un segment duodénal. Dans les deux cas, le rythme des ondes lentes à 17-18 min du côlon est diminué et la réduction est superposable à celle observée en aval de la $1^{\mathrm{e}}$ et de la $2^{\mathrm{e}}$ section duodénale ou au niveau de la zone refroidie.

En revanche, le rythme d'ondes lentes du côlon à $7-9 / \mathrm{min}$ n'est pas modifié. Enfin, il n'existe aucune relation entre l'apparition des salves de potentiels d'action sur le duodenum et celle enregistrée au niveau colique.

Cette étude permet de conclure que seul le rythme d'ondes lentes à 7-9 par minute, observé sur le côlon, est d'origine intrinsèque et que le deuxième rythme à 18-19/min résulte d'une interférence duodénale. 


\section{References}

BUENO L., GARCIA-VILLAR R., RUCKEBUSCH Y., 1977. Activité électrique du côlon chez le chien éveillé. C. R. Acad. Sci. Paris, Sér. D, 16, 1463-1466.

CAPRILLI R., VERNIA P., FRIERI G., MELCHIORRI P., 1975. The electrical rhythms in the colon. Rendic. Gastroenterol., 7, 65-66.

CHRISTENSEN J., CAPRILLI R., LUND G. F., 1969. Electric slow-waves in circular muscle of cat colon. Am. J. Physiol., 217, 771-776.

EL-SHARKAWY TY. MCDONALD W., DIAMANT BE., 1979. Electrical and motor activities of canine colon in vitro. Gastroenterology, 76, $1128 \mathrm{~A}$.

LORD M. G., HUTTON M., WINGATE D. L., 1979. Fast slow-waves in the canine colon. Gastroenterology, 76, 1188A.

MIZHOROKOVA Z., PAPASOVA M., 1977. Unified rhythm of the slow wave of the small and large intestines in the ileocecal region. C. R. Acad. Bulg. Sci., 29, 1535-1538.

RUCKEBUSCH Y., 1970. The electrical activity of the digestive tract of the sheep as an indication of the mechanical events in various regions. J. Physiol. Lond., 210, 857-882.

VANASIN B., USTACH T. J., SCHUSTER M. M., 1974. Electrical and motor activity of human and dog colon in vitro. Johns Hopkins med. J., 134, 201-210. 